\title{
Pediatric COVID-19-associated rhabdomyolysis: a case report
}

\author{
Ashley M. Gefen ${ }^{1} \cdot$ Nancy Palumbo $^{2} \cdot$ Suresh K. Nathan ${ }^{2} \cdot$ Pamela S. Singer $^{1} \cdot$ Laura J. Castellanos-Reyes $^{1}$. \\ Christine B. Sethna ${ }^{1}$ (it)
}

Received: 12 May 2020 / Accepted: 13 May 2020 / Published online: 23 May 2020

(C) IPNA 2020

\begin{abstract}
COVID-19 is the illness caused by infection with the novel coronavirus SARS-CoV-2. Although myalgia is common in adults, it has not been noted as a common symptom in children. There have been a few reported cases of COVID-19-associated rhabdomyolysis in adults. This case report describes a 16-year-old boy who presented with fever, myalgias, mild shortness of breath with exertion, and dark-colored urine. COVID-19 PCR was positive. His initial creatinine kinase (CK) level was 427,656 U/L. Serum creatinine was normal for age. He was treated with isotonic intravenous fluids containing sodium bicarbonate to maintain urine output of $100-200 \mathrm{~mL} / \mathrm{h}$ and urine $\mathrm{pH}>7.0$. His serum creatinine remained normal throughout the hospital stay and he was discharged on hospital day 12 with a CK of $6526 \mathrm{U} / \mathrm{L}$. To our knowledge, no pediatric cases of COVID-19-associated rhabdomyolysis have been previously reported. Adult cases of rhabdomyolysis have been reported and a few reports have noted patients with elevated CK levels without rhabdomyolysis. Given this pediatric case of COVID-19-associated rhabdomyolysis, pediatric clinicians should be aware of this complication and manage fluids appropriately in order to prevent acute kidney injury.
\end{abstract}

Keywords SARS-CoV-2 $\cdot$ Coronavirus $\cdot$ Creatine kinase $\cdot$ Children

\section{Introduction}

COVID-19 is the illness caused by infection with the novel coronavirus SARS-CoV-2. SARS-CoV-2 first emerged in China in December 2019 and shortly thereafter spread worldwide. In adults, the most common presenting symptoms are fever (76$91 \%)$, cough (63-65\%), fatigue (38.5-50\%), dyspnea (14-44\%), anorexia (12-24\%), diarrhea (15-28\%), and myalgia (11-22\%) [1-3]. In children, fever (36-41.5\%), cough (19-48.5\%), and diarrhea (9-12\%) are most common [4-6]. Although myalgias are common in adults, no studies in children noted the presence of myalgias $[4,5]$. There have been a few reported cases of COVID-19-associated rhabdomyolysis in adults, but no such cases have been reported in children [7-10].

Rhabdomyolysis is defined as the breakdown of skeletal muscle leading to leaking of muscle contents into the extracellular fluid [11]. Although there is no official consensus, it is

Christine B. Sethna

csethna@northwell.edu

1 Division of Pediatric Nephrology, Department of Pediatrics, Cohen Children's Medical Center of New York, New Hyde Park, NY, USA

2 Department of Pediatrics, Cohen Children's Medical Center of New York, New Hyde Park, NY, USA usually defined by a serum creatine kinase (CK) of $>1000 \mathrm{U} /$ $\mathrm{L}$, which is five times the upper limit of normal [11]. Patients with rhabdomyolysis can be asymptomatic or present with myalgia, weakness, myoglobinuria with dark urine, significant electrolyte imbalance, and acute kidney injury [11]. Rhabdomyolysis in children is commonly caused by viral myositis, trauma, connective tissue disorders, and drug overdose [11]. The most common viral causes of rhabdomyolysis are influenza A and B viruses followed by HIV and enteroviruses [12]. Rarely, other viruses have been reported to cause rhabdomyolysis, including coronaviruses such as SARSCoV-1 $[12,13]$. Here we present a case of pediatric COVID-19-associated rhabdomyolysis.

\section{Case report}

A 16-year-old boy with autism spectrum disorder, attention deficit hyperactivity disorder, morbid obesity, obstructive sleep apnea, and eczema presented with fever, myalgias, shortness of breath with exertion, and dark-colored urine. Five days prior to admission, he began to feel fatigue. Four days prior to admission, he noted myalgias of his arms, legs, abdomen, and back, as well as mild shortness of breath on 
exertion. One day prior to admission, he was evaluated by an urgent care center where he was febrile to $38.9^{\circ} \mathrm{C}$. He denied any congestion, rhinorrhea, anosmia, inability to taste, dysuria, nausea, vomiting, or diarrhea. Of note, he was found to have cola-colored urine. When asked about the duration of dark urine, he stated it had been occurring for 2 days, but his mother was not certain that his estimation was accurate given his autism spectrum disorder. He took acetaminophen intermittently in the days prior and denied taking any non-steroidal anti-inflammatory agents. The family history was significant for hypertension and type 2 diabetes mellitus.

In the emergency department, vital signs were as follows: maximum temperature of $37.8^{\circ} \mathrm{C}$, heart rate of $122 \mathrm{BPM}$, respiratory rate of 18-20 breaths/min, and oxygen saturation of 99$100 \%$ on room air. His blood pressure was initially elevated at 133/87 mmHg but lowered to normal range without intervention. He was well appearing on exam, with the only focal findings being pharyngeal erythema and diffuse abdominal pain. Initial laboratory work-up revealed a slight elevation in white blood cell count at $10.74 \mathrm{~K} / \mathrm{uL}$ and slightly low platelets at $138 \mathrm{~K} / \mathrm{uL}$. Serum creatinine was normal for age at $0.89 \mathrm{mg} / \mathrm{dL}$ and electrolytes were within normal range. AST and ALT were elevated at $839 \mathrm{U} / \mathrm{L}$ and $157 \mathrm{U} / \mathrm{L}$, respectively, and GGT was normal at $37 \mathrm{U} / \mathrm{L}$. Urinalysis showed a $\mathrm{pH}$ of 6.0 , large blood with 11$25 \mathrm{RBC} / \mathrm{HPF}$ and 6-10 WBC/HPF. Random urine protein-tocreatinine ratio was elevated at $0.81 \mathrm{mg} / \mathrm{mg}$. Kidney ultrasound with Doppler and abdominal ultrasound were normal. Respiratory pathogen PCR panel was negative, but COVID-19 PCR was positive. Hepatitis and cytomegalovirus serologies were negative. Epstein-Barr serologies were indicative of resolved past infection. Antistreptolysin $\mathrm{O}$ screen was not elevated and throat culture was negative. $\mathrm{C} 3$ and $\mathrm{C} 4$ were normal. Antinuclear antibody, double-stranded DNA, and antiglomerular basement membrane $\operatorname{IgG}$ results were all negative. The patient's CK level was 427,656 U/L.

On admission, vital signs were as follows: weight $162 \mathrm{~kg}$, body mass index $54.3 \mathrm{~kg} / \mathrm{m}^{2}$ (>99th percentile), blood pressure $122 / 72 \mathrm{mmHg}$, temperature $37.7^{\circ} \mathrm{C}$, heart rate $110 \mathrm{BPM}$, respiratory rate 20 breaths/min, and oxygen saturation of 98 $100 \%$ on room air. Physical exam was notable for obesity, acanthosis nigricans, and tenderness to palpation of distal anterior lower legs. Repeat CK was 296,396 U/L. Urine myoglobin was sent but did not result. His sodium decreased to $130 \mathrm{mmol} / \mathrm{L}$, albumin decreased to $3.2 \mathrm{~g} / \mathrm{dL}$, and creatinine remained normal for age at $0.68 \mathrm{mg} / \mathrm{dL}$. Ferritin was normal, but procalcitonin $(0.22 \mathrm{ng} / \mathrm{mL})$, lactate dehydrogenase (2184 U/L), C-reactive protein $(24.9 \mathrm{mg} / \mathrm{L})$, and troponin $(58 \mathrm{ng} / \mathrm{L})$ were elevated. Echocardiogram was normal. Toxicology screen was negative. Incidentally, hemoglobin A1c was found to be elevated in the diabetic range at $8.2 \%$. $\mathrm{He}$ was given a $1000 \mathrm{~mL}$ normal saline bolus and started on isotonic intravenous fluids containing sodium bicarbonate and potassium chloride at $200 \mathrm{~mL} / \mathrm{h}$.
On hospital day 2, CK was down to 108,059 U/L. Sodium and albumin normalized. Urine $\mathrm{pH}$ was $>7.0$. On hospital day 4 , he continued to have significant myalgias requiring acetaminophen and morphine. His fluids were reduced to $100 \mathrm{~mL} /$ $\mathrm{h}$ as his CK had decreased to $53,977 \mathrm{U} / \mathrm{L}$, and his serum creatinine remained normal. However, on hospital day 6, his CK doubled from the previous day to $159,675 \mathrm{U} / \mathrm{L}$, and his fluids were increased back to $200 \mathrm{~mL} / \mathrm{h}$. His blood pressures became persistently elevated and amlodipine $5 \mathrm{mg}$ daily was initiated. Starting on hospital day 7, he no longer complained of myalgias and did not require further analgesic medications. On hospital day 9, his CK was 36,294 U/L and his urine was negative for blood, so the fluid rate was decreased. Urine myoglobin was resent and was elevated at $45 \mathrm{mcg} / \mathrm{L}$. On hospital day 11 , his $\mathrm{CK}$ was $11,732 \mathrm{U} / \mathrm{L}$ and urine remained negative for blood. His fluids were stopped along with his amlodipine as his blood pressures normalized. He was discharged on hospital day 12 with a CK of $6526 \mathrm{U} / \mathrm{L}$. The CK trend is illustrated in Fig. 1.

\section{Discussion}

Herein, we present a case of severe rhabdomyolysis without acute kidney injury that was associated with COVID-19 infection in a pediatric patient. To our knowledge, no cases of COVID-19-associated rhabdomyolysis have been previously reported in children or adolescents.

A few adult cases have been reported recently, none of which had CK levels nearly as high as our patient's. In a series of 1099 patients with COVID-19 in China, 2 patients were diagnosed with rhabdomyolysis. The ages of these patients were not specified, but of all the study patients, $<1 \%$ of patients were less than 15 -years-old [10]. Another group in China analyzed the autopsies of 26 adult patients with COVID-19 and found pigmented casts associated with high CK levels in 3 patients [7]. One case of

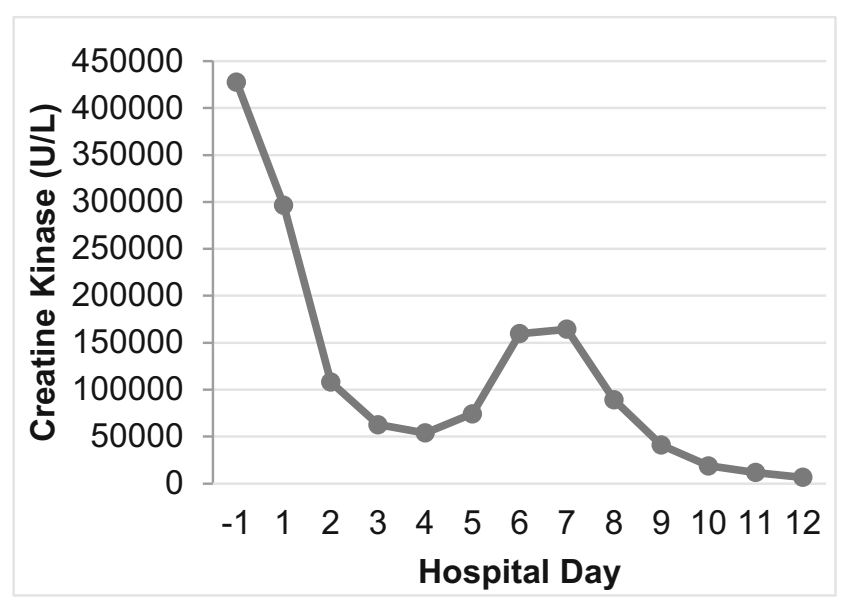

Fig. 1 Creatine kinase trend over time 
COVID-19-associated rhabdomyolysis was reported in a 60-year-old male in Wuhan, China, with a maximum CK of 17,434 U/L without any subsequent acute kidney injury [14]. The only case of COVID-19-associated rhabdomyolysis reported in the USA was of an 88-year-old male with a maximum $\mathrm{CK}$ of $13,581 \mathrm{U} / \mathrm{L}$ with subsequent development of mild acute kidney injury that resolved with intravenous fluid administration [8].

Several studies from China reported patients with elevated CK levels without development of rhabdomyolysis. In a study of 95 adults, 12 had CK levels 200-400 U/L, 9 had levels 400-600 U/L, and 7 had levels $>600 \mathrm{U} / \mathrm{L}$ [15]. In a study of 91 adults, 14 had CK levels $>190 \mathrm{U} / \mathrm{L}$ and 15 had myalgias, but there is no indication if those with elevated $\mathrm{CK}$ were those with myalgias [3]. In a study of 161 adults, 17 had CK levels $>190 \mathrm{U} / \mathrm{L}$ and 18 had myalgias, but there is no indication if those elevated CK were those with myalgias [1]. The only pediatric study that assessed CK levels involved 32 children and found that no patients had rhabdomyolysis and only one patient had CK > $170 \mathrm{U} / \mathrm{L}$ [4].

In general, the pathogenesis of different types of viral rhabdomyolysis has been debated and includes direct invasion of the muscle by virus, cytokine storm resulting in muscle damage, and muscle injury by circulating viral toxins. Chen et al. postulated that SARS-CoV-1-associated rhabdomyolysis was secondary to cytokine storm rather than direct viral invasion due to the presence of high inflammatory markers and the lack of viral particles on muscle biopsies [13]. There are no reports of muscle biopsies in patients with COVID-19-associated rhabdomyolysis, but similar to SARS, COVID-19 is also associated with high inflammatory markers. This may indicate that rhabdomyolysis in COVID-19 could be cytokine-mediated.

In conclusion, this case illustrates a pediatric patient who presented with myalgia and severe rhabdomyolysis in the setting of COVID-19 infection. Rhabdomyolysis and elevated CK may be under-recognized complications of COVID-19 in pediatrics. Given this pediatric case of COVID-19-associated rhabdomyolysis and the multiple reports in adults, pediatric clinicians should be aware of this complication. We recommend checking $\mathrm{CK}$ levels in pediatric patients presenting with myalgia, especially those with urinary changes or acute kidney injury. When treating rhabdomyolysis, aggressive fluid administration is important to prevent acute kidney injury. However, it is especially important to monitor for signs of heart failure and pulmonary edema as these complications can occur in COVID-19 patients even without aggressive fluid administration.

Authors' contributions AG performed the literature search. AG and CS wrote the first draft of the manuscript. All authors contributed to the critical appraisal of the manuscript and have approved the final version of the manuscript that was submitted.
Data availability Data will be made available upon request.

\section{Compliance with ethical standards}

Conflicts of interest The authors declare that they have no conflict of interest.

\section{References}

1. Zheng F, Tang W, Li H, Huang YX, Xie YL, Zhou ZG (2020) Clinical characteristics of 161 cases of corona virus disease 2019 (COVID-19) in Changsha. Eur Rev Med Pharmacol Sci 24:34043410

2. Chen T, Wu D, Chen H, Yan W, Yang D, Chen G, Ma K, Xu D, Yu H, Wang H, Wang T, Guo W, Chen J, Ding C, Zhang X, Huang J, Han M, Li S, Luo X, Zhao J, Ning Q (2020) Clinical characteristics of 113 deceased patients with coronavirus disease 2019: retrospective study. BMJ 368:m1091

3. Zhao XY, Xu XX, Yin HS, Hu QM, Xiong T, Tang YY, Yang AY, Yu BP, Huang ZP (2020) Clinical characteristics of patients with 2019 coronavirus disease in a non-Wuhan area of Hubei Province, China: a retrospective study. BMC Infect Dis 20:311

4. Qiu H, Wu J, Hong L, Luo Y, Song Q, Chen D (2020) Clinical and epidemiological features of 36 children with coronavirus disease 2019 (COVID-19) in Zhejiang, China: an observational cohort study. Lancet Infect Dis. https://doi.org/10.1016/S1473-3099(20) 30198-5

5. Lu X, Zhang L, Du H, Zhang J, Li YY, Qu J, Zhang W, Wang Y, Bao S, Li Y, Wu C, Liu H, Liu D, Shao J, Peng X, Yang Y, Liu Z, Xiang Y, Zhang F, Silva RM, Pinkerton KE, Shen K, Xiao H, Xu S, Wong GWK (2020) SARS-CoV-2 infection in children. N Engl J Med 382:1663-1665

6. Zheng F, Liao C, Fan QH, Chen HB, Zhao XG, Xie ZG, Li XL, Chen CX, Lu XX, Liu ZS, Lu W, Chen CB, Jiao R, Zhang AM, Wang JT, Ding XW, Zeng YG, Cheng LP, Huang QF, Wu J, Luo XC, Wang ZJ, Zhong YY, Bai Y, Wu XY, Jin RM (2020) Clinical characteristics of children with coronavirus disease 2019 in Hubei, China. Curr Med Sci 40:275-280

7. Su H, Yang M, Wan C, Yi LX, Tang F, Zhu HY, Yi F, Yang HC, Fogo AB, Nie X, Zhang C (2020) Renal histopathological analysis of 26 postmortem findings of patients with COVID-19 in China. Kidney Int. https://doi.org/10.1016/j.kint.2020.04.003

8. Suwanwongse K, Shabarek N (2020) Rhabdomyolysis as a presentation of 2019 novel coronavirus disease. Cureus 12:e7561

9. Ronco C, Reis T (2020) Kidney involvement in COVID-19 and rationale for extracorporeal therapies. Nat Rev Nephrol. https://doi. org/10.1038/s41581-020-0284-7

10. Guan WJ, Ni ZY, Hu Y, Liang WH, Ou CQ, He JX, Liu L, Shan H, Lei CL, Hui DSC, Du B, Li LJ, Zeng G, Yuen KY, Chen RC, Tang CL, Wang T, Chen PY, Xiang J, Li SY, Wang JL, Liang ZJ, Peng YX, Wei L, Liu Y, Hu YH, Peng P, Wang JM, Liu JY, Chen Z, Li G, Zheng ZJ, Qiu SQ, Luo J, Ye CJ, Zhu SY, Zhong NS (2020) Clinical characteristics of coronavirus disease 2019 in China. N Engl J Med 382:1708-1720

11. Al-Ismaili Z, Piccioni M, Zappitelli M (2011) Rhabdomyolysis: pathogenesis of renal injury and management. Pediatr Nephrol 26:1781-1788

12. Crum-Cianflone NF (2008) Bacterial, fungal, parasitic, and viral myositis. Clin Microbiol Rev 21:473-494

13. Chen LL, Hsu CW, Tian YC, Fang JT (2005) Rhabdomyolysis associated with acute renal failure in patients with severe acute respiratory syndrome. Int J Clin Pract 59:1162-1166 
14. Min J, Tong Q (2020) Rhabdomyolysis as potential late complication associated with COVID-19. Emerg Infect Dis 26(7). https:// doi.org/10.3201/eid2607.200445

15. Zhang G, Zhang J, Wang B, Zhu X, Wang Q, Qiu S (2020) Analysis of clinical characteristics and laboratory findings of 95 cases of 2019 novel coronavirus pneumonia in Wuhan, China: a retrospective analysis. Respir Res 21:74

Publisher's note Springer Nature remains neutral with regard to jurisdictional claims in published maps and institutional affiliations. 